\title{
KẾT QUẢ CAN THIỆP NỘI MACH ĐIỀU TRI RÒ ĐộNG MACH CẢNH XOANG HANG CHẤN THƯƠNG BẰNG VÒNG XOẮN KIM LOẠI: NGHIÊN CỨU 74 TRƯỜNG HỢP
}

\author{
Trần Minh Hoàng1, Lê Văn Phước ${ }^{2}$, Nguyễn Huỳnh Nhật Tuấn ${ }^{2}$, \\ Nghiêm Phương Thảo ${ }^{3}$, Lê Văn Khoa ${ }^{2}$
}

\section{TÓM TẮT}

Mục tiêu: mô tả một số đặc điểm lâm sàng, đặc điểm chẩn đoán hình ảnh và kết quả điều trị can thiệp nội mạch trên bệnh nhân rò động mạch cảnh xoang hang chấn thương (RĐMCXHCT). Phương pháp: Thiết kế nghiên cứu loạt ca, hồi cứu bệnh án của 74 bệnh nhân RĐMCXHCT được điều trị bằng can thiệp nổi mạch (CTTNM) dùng vòng xoắn kim loại tại Bệnh viện Chợ Rây từ 01/2019 đển 06/2021. Hiệu quả và độ an toàn được đánh giá bằng các biến số: tắc hoàn toàn, tắc bán phần, cải thiêm lâm sàng, bảo tồn động mạch cảnh, biến chứng thủ thuật, tái phát trong 3 tháng theo dõi sau can thiêp. Kết quả: bênh nhân (BN) có cải thiên lâm sàng đạt được 73/74 BN $(98,6 \%)$, trong đó tắc hoàn toàn $67 \mathrm{BN}$, tắc bán phần $6 \mathrm{BN}$ và ca thất bại điêuu trị $1 \mathrm{BN}$. Bảo tồn được động mach cảnh là 69/74 BN $(93,2 \%)$. Biến chứng liền quan thủ thuật với 2 BN thiếu máu não thoáng qua, 1 BN có hình ảnh̀ xâm nhập coil vào lòng động mạch cảnh và 1 BN yễu nửa người bên trái. Không có trường hợp nào tái phát hay tử vong trong 3 tháng theo dối sau can thiệp. Kết luận: Can thiệp nội mạch dùng vòng xoắn kim loại là một phương pháp an toàn và hiệu quả cao để điều trị RĐMCXHCT. Phương pháp này tăng khả năng bảo tồn động mạch cảnh.

Tư khóa: Rò động mạch cảnh xoang hang chấn thương, can thiệp nội mạch.

\section{SUMMARY}

ENDOVASCULAR TREATMENT OF TRAUMATIC CAROTID CAVERNOUS FISTULA WITH DETACHABLE COILS: STUDY OF 74 CASES

Obiectives: describe some clinical features, imaging characteristics and treatment results by Endovascular treatment (ET) on patient with Traumatic carotid cavernous fistula (TCCF). Methods: Case series study design, retrospective medical records of 74 patients with TCCFs, who was treated by ET with detachable coils at Choray hospital from $01 / 2019$ to $06 / 2021$. The efficacy and safety were evaluated by variants: Complete or partial occlusion, clinical improvenment, the preservation of the internal carotid artery (ICA), procedural complications and recurrence at the 3-month follow-up after ET.

${ }^{1}$ Bênh viên Đai hoc Y Dược TP. Hồ Chí Minh 2Bệnh viện Chợ Rẫy,

${ }^{3}$ Trường Đai hoc Y khoa Pham Ngoc Thach.

Chịu trách nhiệm chính: Lê Văn Khoa

Email: levankhoard@gmail.com

Ngày nhận bài: 23.8.2021

Ngày phản biên khoa hoc: 25.10 .2021

Ngày duyệt bài: 3.11 .2021
Results: Patients with clinical improvement achieved $73 / 74$ patients $(98.6 \%)$, of which complete occlusion was 67 patients, partial occlusion in 6 patients and treatment failure in 1 patient. The preservation of the ICA was observed in 69/74 (93.2\%) cases. Procudrerelated complications were recorded with 2 cases of transient ischemic attack, 1 case with coils herniation into the ICA and 1 case with left-side weakness. No cases of recurrence or death were reported within 3 months of clinical follow-up after ET. Conclusions: Endovascular treatment with detachable coils is a highly safe and effective method to treat traumatic carotid cavernous fistula. Detachable coils may increase the ability to preserve the internal common artery.

Keywords: Traumatic carotid cavernous fistula, endovascular treatment.

\section{I. ĐẶT VẤN ĐỀ}

Rò động mạch cảnh do chấn thương là sự thông nối bất thường từ hệ thống động mạch cảnh và xoang hang, được gọi là loại $A$ theo phân loại của Barrow, nguyên nhân phổ biến nhất của bệnh là do chấn thương đầu [3]. Ở Việt Nam do tỷ lệ tai nạn giao thông do xe máy cao, tỷ lệ bệnh tương đướng 0,5\% [4]. Bệnh có thể gây ù tai, đỏ mắt, lồi mắt, giảm thị lực, ảnh hưởng đến chất lượng cuộc sống của $B N$ và đôi khi gây liệt dây thần kinh sọ và hậu quả nặng hơn là chảy máu mũi ô ạt hoặc xuất huyết não, làm tăng tỷ lệ khuyết tật và tử vong [9].

Phương pháp điêu trị tiêu chuẩn đối với RĐMCXHCT là CTNM sử dụng bóng tắc, tỷ lệ thành công về mặt kỹ thuật là $80-90 \%$, tuy nhiên nhược điểm là có khả năng xẹp hoặc võ bóng, tái phát cao và tỷ lệ phải tắc động mạch cảnh trong cao, thêm vào đó vật liệu tắc bằng bóng không thường xuyên sẵn có [4],[9]. Hiện nay ở Châu Á nói chung và tại Việt Nam có rất ít nghiên cứu đánh giá vai trò của CTNM với vòng xoắn kim loại trong điều trị RĐMCXHCT, nhưng chỉ giới hạn ở một vài trường hợp được báo cáo,[6]. Do đó nghiên cứu này thực hiện nhằm bổ sung thông tin dữ liệu về đặc điểm lẩm sàng, cận lâm sàng và kết quả điểu trị RĐMCXHCT bằng CTNM.

II. ĐỐI TƯỢNG VÀ PHƯƠNG PHÁP NGHIÊN CỨU

2.1. Đối tượng nghiên cứu. Đối tượng nghiên cứu gồm 74 bệnh nhân RĐMCXHCT được chẩn đoán trên chụp mạch máu xóa nền (DSA) 
và điêu trị bằng phương pháp CTNM sử dụng vòng xoắn kim loai tại Khoa Chẩn đoán hình ảnh, Bệnh viện Chợ Rẫy, từ tháng 01/2019 đến tháng $6 / 2021$.

2.2. Thiết kế nghiên cứu. Thiết kế nghiên cứu báo cáo loạt ca.

2.3. Phương pháp thu thập số liệu. Hồi cứu hồ sơ bệnh án của $B N$ thỏa các điều kiện chọn mẫu.

Các biến số được thu thập bao gồm: đặc điểm cá nhân, lâm sàng, hiệu quả lâm sàng, tái phát, bảo tồn động mạch cảnh, biến chứng, tái phát trong vòng 3 theo dõi tháng. Thủ thuật thành công được xác định là tắc hoàn toàn khi không còn thây dòng rò hoặc tắc gần hoàn toàn khi chỉ còn thấy dẫn lưu tînh mạch xuôi dòng, không còn âm thổi.

2.4. Phương pháp điêu trị trên bệnh nhân. BN đã được chẩn đoán bằng chụp mạch xóa nền (DSA) (Artis Zee biplane, Siemens) và đánh giá tuần hoàn bàng hệ bằng thử tắc bóng của động mạch cảnh trong cùng bên rò.

Phương pháp điều trị đã thực hiện trên BN là tiếp cận đường động mạch: Đặt ống thông vào động mạch cảnh trong, tái tạo 3D để xác định chính xác lỗ rò. Tiếp theo, đưa vi ống thông vào lỗ rò thông qua hướng dẫn bản đồ đường đi mạch máu. Bơm thuốc cản guang qua ống thông xác nhận chính xác vị trí lố rò và tắc lố rò với hình dạng và kích thước coils thích hợp ((Penumbra Inc, Alameda, CA, Mỹ), (Microvention, Tustin $C A$, Mỹ). Nếu các vòng coils có xu hướng xâm nhập vào lòng của động mạch cảnh, cần phải dùng thêm bóng chạn ngang qua lỗ rò như Scepter (Microvention, Tustin CA, Mỹ) để bảo tồn động mạch cảnh trong.

Trong trường hợp tiếp cận đường động mạch không thành công, tiếp cận đường tĩnh mạch sẽ được áp dụng, đặt ống thông vào tĩnh mạch cảnh trong và sau đó đưa vi ống thông vào lỗ rò từ xoang đá dưới hoặc tĩnh mạch mắt trên hoặc xoang liên hang. Các bước tiếp theo tương tự như tiếp cận đường động mạch. Một số trường hợp khó, cần kết hợp cả hai cách tiếp cận này vào đường rò. Một số khác để không dùng bóng mà hạn chế vòng xoắn kim loại di chuyển sẽ dùng đưa 2 vi thông cùng lúc đặt vòng xoắn kim loại vào lỗ rò.

Chụp DSA được kiểm tra ngay sau can thiệp để đánh giá hiệu quả và biến chứng tắc mạch.

2.5. Xử lý và phân tích số liệu. Dữ liệu được xử lý và phân tích bằng phần mềm STATA 14.0. Thống kê mô tả với tần số $(n)$ và tỷ lệ $(\%)$ đối với biến số định tính và trung bình, độ lệch chuẩn (TB \pm ĐLC) với biến số định lượng.

2.6. Vấn đề đạo đức trong nghiên cứu. Nghiên cứu khảo sát dữ liệu từ hồ sơ bệnh án, không can thiệp trên $B N$, không thu thập thông tin tiết lộ danh tính cá nhân và mọi dữ liệu được bảo mật. Nghiên cứu được sự chấp thuận của Bệnh viện Chợ Rẫy và đã được thông qua bởi Hội đồng đạo đức trong nghiển cứu y sinh học Trường Đại học Y khoa Phạm Ngọc Thạch.

\section{KẾT QUẢ NGHIÊN CỨU}

Trong 74 BN, tỷ lệ nam là $79,7 \%$ và nữ chỉ $20,3 \%$. Tuổi trung bình là $36,2 \pm 14,1$. Tai nạn giao thông là nguyên nhân thường gặp nhất của RĐMCXH, với 93,2\%.

3.1. Đặc điểm lâm sàng. Các triệu chứng lâm sàng phổ biến nhất bao gồm đỏ và lồi mắt $(94,6 \%)$ và âm thổi ở mắt $(86,5 \%)$, giảm thị lực $(70,3 \%)$, ù tai $(71,6 \%)$ và chảy máu mũi ở $4 / 74$ ca $(5,4 \%)$, xuất huyết dưới nhện $1 \mathrm{ca}$.

\section{2. Đắc điểm hình ảnh và điêu trị can} thiệp nội mạch. RĐMCXHCT kết hợp với giả phình mạch kèm theo ơ $14 / 74(18,9 \%)$ ca. Phương pháp tiếp cận bằng đường động mạch vào lỗ rò là chủ yếu, nếu thất bại mới chuyển sang đường tĩnh mạch, trong đó đường tĩnh mạch xoang đá dưới là hay được chọn hơn là tĩnh mạch mắt trên hay xoang liên hang (bảng 1).

Bàng 1. Đường tiếp cận vào lố rò tư động mạch hoặc tînh mạch

\begin{tabular}{|c|c|c|}
\hline Đường tiếp cận & $\begin{array}{c}\text { Tân số } \\
\text { (n) }\end{array}$ & $\begin{array}{c}\text { Tỉ lệ } \\
\mathbf{\%}\end{array}$ \\
\hline Động mạch cảnh trong & 60 & 81,1 \\
\hline Tînh mạch xoang đá dưới & 9 & 12,2 \\
\hline Tînh mạch mắt trên & 3 & 4,1 \\
\hline Tînh mạch xoang liên hang & 2 & 2,6 \\
\hline Tống cộng & $\mathbf{7 4}$ & $\mathbf{1 0 0}$ \\
\hline
\end{tabular}

Kỹ thuật hồ trợ vòng xoắn kim loại gồm có bóng trợ ngang qua lỗ rò và kỹ thuật 2 vi ống thông được tóm tắt theo bảng 2.

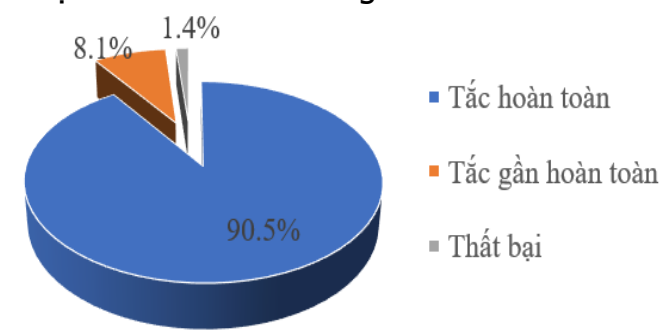

Biều đồ 1. Múc độ tắc lỗ rò ĐMCXHCT

Cải thiện mức độ các triệu chứng lâm sàng (biểu đồ 2). Đặc biệt có 4 ca giả phình mạch chảy máu mũi và 1 ca có giả phình mạch gây xuất huyết dưới nhện, tất cả đều được tằc bằng vòng xoắn kim loại thành công. 


Bảng 2. Dưng cụ can thiệp hỗ trợ vòng
xoăn kim loại
\begin{tabular}{|c|c|c|}
\hline Can thiệp hô trợ & Tân số & Tỉ lệ \% \\
\hline Vòng xoắn kim loại đơn thuần & 57 & 77,0 \\
\hline Bóng trợ ngang lô rò & 16 & 21,6 \\
\hline Kỹ thuật 2 vi ống thông & 1 & 1,4 \\
\hline Tống cộng & $\mathbf{7 4}$ & $\mathbf{1 0 0}$ \\
\hline
\end{tabular}

Thành công thủ thuât là $73 / 74(98,6 \%) \mathrm{ca}$, với mức độ tắc độ (biểu đồ 1 ). Bảo tồn động mạch cảnh trong với $69 / 74$ (93,2\%) ca, phải tắc động mạch cảnh để điều trị lỗ rò $5 / 74(6,8 \%)$ ca.

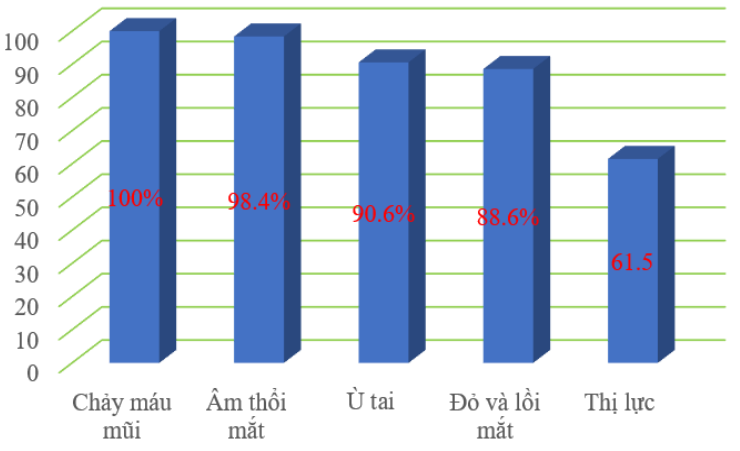

Biều đồ 2. Mức độ cải thiện triệu chứng lâm sàng sau can thiệp

Biến chứng tụ máu tại vị trí đâm kim động mạch đùi thường gặp nhất là $4,1 \%$. Các biến chứng cụ thể liên quan đến xâm nhập vòng xoắn kim loại vào lòng mạch động mạch cảnh trong 1 $\mathrm{BN}$ và cơn thiếu máu não thoáng qua $2 \mathrm{BN}, 1 \mathrm{BN}$ bị biến chứng nặng gây yếu nữa người bên trái. Không có bất kỳ trường hợp tái phát hoặc tử vong nào được báo cáo trong 3 tháng theo dõi lâm sàng.

\section{MINH HỌA TRƯỜNG HợP}

\section{Trường hơp 1.}

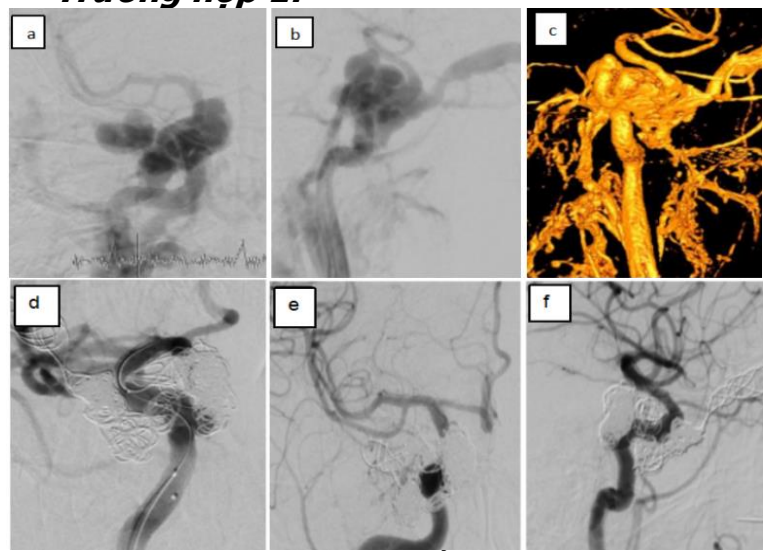

Hình 1. $B N$ nam, 31 tuổi nhập viện vì đỏ lồi mắt phải, 2 tuần sau chấn thương đầu. Hình DSA: RĐMCXHCT phải với giãn lớn xoang hang, dẫn lưu tĩnh mạch mắt trên ở tư thế thẳng (a) nghiêng 90 độ (b) và hình ảnh tái tạo 3D (c).
CTNM bằng bóng trợ coils $(\mathrm{d})$ và sau khi tắc hoàn toàn lô̂ rò ở tư thế thẳng (e) và nghiêng 90 độ (f). Kết quả: Cải thiện các triệu chứng.

\section{Trường hợp 2:}

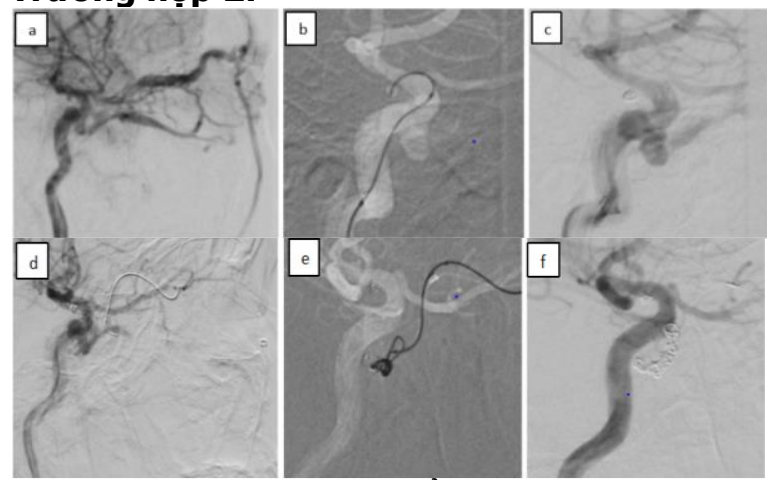

Hình 2: BN nam, 32 tuối vào viện vì đau đầu, đỏ mắt 5 ngày sau chấn thương đầu. Hình DSA: RĐMCXHCT lỗ rò nhỏ với dẫn lưu tĩnh mạch mắt trên, kết hợp với giả phình mạch (a). Đưa vi ống thông vào giả phình mạch (b), sau khi tắc hoàn toàn giả phình mạch (c). Tiếp cận đường tĩnh mạch đưa vi ống thông vào tĩnh mạch mắt trên vào lỗ rò $(\mathrm{d})$, đang tắc lỗ rò bằng coils $(\mathrm{e})$, kiểm tra tắc hoàn toàn $(\mathrm{f})$. Kết quả lâm sàng: cải thiện các triệu chứng sau can thiệp

\section{BÀN LUẬN}

Trong 74 ca bệnh được điều trị, hầu hết là các BN trẻ tuổi với nam giới là chủ yếu $(79,7 \%)$ I, đây là đối tượng có các yếu tố nguy cơ đi kèm như uống rượu, hoat động tham gia tai nạn giao thông. Theo nghiên cứu của Thohar Arifin Muhamad, cũng hầu hết $\mathrm{BN}$ bị RĐMCXHCT là nam giới và trẻ tuổi [1].

Phương pháp tiếp cận đường động mạch là được sủ dụng nhiều nhất vì phương pháp tiếp cận này là thông thường và chuẩn mực, trong đó thời gian thủ thuâtt được rút ngắn và việc đưa vi ống thông vào lổ rò trở nên dễ dàng hơn [8]. Nếu tiếp cận đường động mạch không thành công, thì đường tĩnh mạch sẽ được thực hiện để tiếp cận vào lỗ rò thông qua xoang đá dưới hoặc tĩnh mạch mắt trên hoặc xoang liên hang [9].

Kỹ thuật chẹn bóng trợ coils rất hữu ích trong việc ngăn ngừa sự xâm nhập của các vòng coils vào lòng của động mạch cảnh trong và giúp bảo tồn động mạch cảnh. Vì vậy, tỷ lệ bảo tôn được động mạch cảnh trong trong nghiên cứu này là rất cao, lên tới 93,2\%. Theo De Renziz và cs, sử dụng kỹ thuật bóng chen trợ coils đã giúp bảo tồn động mạch cảnh $92 \%$ [5]. Trong khi đó, theo tác giả Chi C.T và $\mathrm{cs}$, với vật liệu thuyên tắc chủ yếu là bằng bóng, tỷ lệ thành công với sự bảo tồn động mạch cảnh chỉ là 66\% [4]. Việc bảo tồn 
động mạch cảnh có ý nghĩa rất lớn vì hầu hết bệnh nhân RĐMCXHCT đều trẻ, nam giởi nằm trong độ tuổi lao động và có thời gian sống còn dài và sư cần thiết để cải thiênn chất lượng cuộc sống [4]. Chúng tôi đã thất bại với một ca do đường rò quá lớn và phức tạp, thêm vào đó tuần hoàn bàng hệ không đủ, nển không thể điều trị bằng cách tắc động mạch cảnh đối với trường hợp này.

Hiệu quả lâm sàng dựa trên thành công kỹ thuật và sự cải thiện các triệu chứng lâm sàng trước và sau can thiệp đã được đánh giá. Theo Permana Galih và cộng sự, CTNM với tắc bằng bóng có tỷ lệ cải thiện triệu chứng lâm sàng với lồi mắt là $89 \%$, đỏ mắt là $92 \%$ và ù tai là $100 \%$. Không có sự khác biệt đáng kể giữa nghiên cứu này và nghiên cứu của Permana về cải thiện lâm sàng sau can thiệp nội mạch.

Giả phình mạch trong nghiên cứu của chúng tôi lên đến $18,9 \%$, trong đó có 4 trường hợp giả võ̃ dẫn đến chảy máu mũi, 1 trường hợp giả phình đoạn nội sọ bị võ̃ dẫn đến xuất huyểt dưới nhện. Tất cả các giả phình mạch được tắc hoàn toàn bằng coils và ghi nhận không có trường hợp nào võ tái phát sau can thiệp, đây là ưu điểm của vật liệu thuyên tắc bằng coils so với tắc bằng bóng trong điều trị RĐMCXHCT kèm giả phình mạch. RĐMCXHCT kết hợp với giả phình mạch cần được điều trị khẩn cấp vì nguy cơ vỡ giả phình mạch cao như đã được khuyến cáo trong nghiên cứu của Moon Hee Han [8].

Các biến chứng thường gặp nhất trong nghiên cứu này là nhe như tụ máu tại chỗ chọc kim vùng bẹn đùi $(4,1 \%)$ và cơn thiếu máu não thoáng qua với $2(2,7 \%)$ ca. Biến chứng này được theo dõi và điêuu trị nội khoa. Biến chứng liên quan thủ thuật trong nghiên cứu này là sự xâm nhập các vòng coils vào lòng mạch động mạch cảnh trong, gây ra nguy cơ huyết khối động mạch não, tuy nhiên, khi được phát hiện trong quá trình thủ thuật, nguy cơ này đã được điều trị nội khoa bằng kháng ngưng tập tiểu cầu kép ngay sau khi can thiệp và BN không có triệu chứng lâm sàng sau đó [6]. Một trường hợp $(1,4 \%)$ biến chứng nặng với yếu nữa người bền trái. Đây là trường hợp rò RĐMCXHCT phức tạp, kết hợp với giả phình mạch khổng lî̀. Vì vậy, chúng tôi quyết định tắc động mạch cảnh, tuy nhiên vài giờ sau can thiệp, BN đột ngột bị yếu nửa người bên trái, điều này được giải thích là do tuần hoàn bàng hệ không đủ cung cấp máu, mặc dù khi thử tắc động mạch cảnh trước đó, BN hoàn toàn không có triệu chứng thiếu máu não [2].
Trong nghiên cứu, không có bất kỳ trường hợp tái phát trong 3 tháng theo dõi sau can thiệp. Nghiên cứu của De Renzis và của Lu C.B. cũng sử dụng coils làm vật liệu tắc mạch, báo cáo tỷ lệ tái phát $0 \%,[5]$. Tuy nhiên, một nghiên cứu của Gao B.L. với bóng tắc, đã ghi nhận tỷ lệ tái phát lên đến $21,1 \%$ [7]. Điều này được giải thích dựa trên đặc tính của vật liệu thuyên tắc, các vòng kim loại khi đã được lấp đầy, huyết khối sẽ có xu hướng tăng dần theo thời gian, khác với bóng tắc là có nguy cơ xẹp bóng, vớ bóng hay di lệch bóng sau can thiệp [9].

Giới hạn của nghiên cứu này là nghiên cứu hồi cứu. Điểm mạnh đó là nghiên cứu trên một số lượng lớn bệnh nhân RĐMCXHCT dùng vòng xoắn kim loại tại một trung tâm can thiệp thần kinh Việt Nam.

\section{KẾT LUẬN}

Tóm lại can thiệp nội mạch tắc rò động mạch cảnh do chấn thương bằng vòng xoắn kim loại là một phương pháp an toàn và hiệu quả. Đặc biệt kỹ thuật này không ghi nhận trường hợp nào tái phát và tỷ lệ bảo tồn động mạch trong cao. Tuy nhiên, cần có các nghiển cứu sâu hơn so sánh các vật liệu thuyên tắc khác trong nhóm chứng để đánh giá hiệu quả của can thiệp nội mạch điều trị rò động mạch cảnh xoang hang do chấn thương bằng vòng xoắn kim loại coils.

\section{TÀI LIỆU THAM KHẢO}

1. Arifin M.T., Akbar M.A., Illyasa W., et al. (2020) "Neuro-endovascular intervention in traumatic carotico-cavernous fistulae: a singlecenter experience". International Journal of General Medicine, 13, 917.

2. Barker D.W., Jungreis $C_{.}$, Horton J., et al. (1993) "Balloon test occlusion of the internal carotid artery: change in stump pressure over 15 minutes and its correlation with xenon CT cerebral blood flow". American journal of neuroradiology, 14 (3), 587-590.

3. Barrow D.L., Spector R.H., Braun I.F., et al. (1985) "Classification and treatment of spontaneous carotid-cavernous sinus fistulas". Journal of neurosurgery, 62 (2), 248-256.

4. Chi C.T., Nguyen D., Duc V.T., et al. (2014) "Direct traumatic carotid cavernous fistula: angiographic classification and treatment strategies study of 172 cases". Interventional Neuroradiology, 20 (4), 461-475.

5. De Renzis A., Nappini S., Consoli A., et al. (2013) "Balloon-Assisted Coiling of the Cavernous Sinus to Treat Direct Carotid Cavernous Fistula: A Single Center Experience of 13 Consecutive Patients". Interventional Neuroradiology, 19 (3), 344-352.

6. Du B., Zhang M., Wang Y., et al. (2016) "A retrospective analysis of 38 carotid cavernous fistula patients treated with balloon-assisted endovascular fistula embolization through simultaneous 
transarterial and transvenous approaches". Int J Clin Exp Med, 9 (10), 19399-19407.

7. Gao B.-L., Wang Z.-L., Li T.-X., et al. (2018) "Recurrence risk factors in detachable balloon embolization of traumatic direct carotid cavernous fistulas in 188 patients". Journal of neurointerventional surgery, 10 (7), 704-707.
8. Han M.H. (2003) "Endovascular Treatment in Direct Carotid Cavernous Fistula". Interventional Neuroradiology, 9 (2_suppl), 55-62.

9. Korkmazer B., Kocak B., Tureci E., et al. (2013) "Endovascular treatment of carotid cavernous sinus fistula: a systematic review". World journal of radiology, 5 (4), 143.

\section{NHÂN 3 TRƯỜNG HỢP ÁP XE NÃO DO VIÊM XOANG: CHẨN ĐOÁN VÀ ĐIỀU TRI TẠI BỆNH VIỆN CHỢ RẪY}

\section{TÓM TẮT}

Qua 3 trường hợp báo cáo, cho chúng ta thây hầu hết triêu chứng của viêm xoang biến chứng áp xe não bao gồm các triệu chứng sau: hội chứng tăng áp lực nội sọ (đau đầu, nôn ói, thay đổi tri giác). Bên canh đó, là triệu chứng về mắt (giảm thị lực/ mù mắt, hạn chế vân nhãn,...). Triêu chứng viêm mũi xoang man thường không râm rộ. 3 trường trường hợp đều được hổ trơ CT scan/ MRI giúp chẩn đoán xác định. Đước điêu trị kết hợp nội khoa, bệnh lý kèm theo và phẫu thuât dẫn lưu ô áp xe, cùng với lây hết bênh tích vùng mũi xoang bị viêm. 3 trường hợp đều điểu trị kéo dài khoảng 4 tuần với kháng sinh qua màng não và đều xuất viện ổn định. Và cho thấy đường lan truyền gây áp xe não từ xoang có thể lan truyền trực tiếp hoặc gián tiếp qua đường máu.

Tư khóa: viêm xoang biến chứng, áp xe não do viêm xoang, áp xe não

\section{SUMMARY \\ DIAGNOSIS AND TREATMENT OF THREE CASES OF SINOGENIC BRAIN ABCESS AT CHO RAY HOSPITAL}

Three cases show the most common symtoms of sinogenic brain abcess including high intracranial pressure syndrome (headache, vomiting, mental disorder). In addition, there arc abnormal symtoms about eyes (loss vision, blindness, limited movement of eyes). The symptoms of chronic rhinosinusitis arc usually not aggressive. These cases took CT scan/ MRI to identify diagnosis clearly. They were cured combined antibiotic therapy and abscess drainage from brain by transnasal endoscopic sinus surgery or craniotomy. All of them improved good their health. And they can went out from the hospital. Sinogenic causes maybe invade directly into brain tissue by anterior skull base or indirectly into bloodstream and move until brain. Keywords: sinogenic brain abcess, sinusitis with brain abcess complaintions, brain abcess.

*Bệnh viện Chỡ Rẫy

Chiu trách nhiểm chính: Ngô Văn Công

Email: congtmh@gmail.com

Ngày nhận bài: 23.8.2021

Ngày phản biên khoa họ: 22.10.2021

Ngày duyệt bài: 1.11.2021
Ngô Văn Công*

\section{GIỚI THIẸU}

Trong kỷ nguyên kháng sinh, biến chứng nôi so do viêm xoang trở nên rất hiếm [1][2]. Tỷ lệ biến chứng 3,7\% được báo cáo ở các bệnh nhân nhập viện với viêm xoang cấp tính hoặc mạn tính [3]. Khả năng viêm xoang đe dọ tính mạng liên quan biến chứng nội sọ bao gồm tụ mủ dưới màng cứng, áp xe ngoài màng cứng hoặc áp xe trong não, viêm màng não, và thuyên tắc xoang tĩnh mạch. Hầu hết các biến chứng liên quan đến xoang trán và sau đó theo thứ tự với xoang sàng, xoang bướm và xoang hàm [4].

Người trưởng thành và trẻ em lớn hơn 6 tuổi được yếu tố nguy cơ cao biến chứng từ nhiễm trùng đường hô hấp trên. Thứ nhất, mạch máu của hệ thống tủy xương là ở giai đoạn cao điểm, và thứ 2 có liên quan đến sự gia tăng cung cấp máu đến xoang trán đang phát triển [1][5].

Các biến chứng nội sọ từ xoang có thể xảy ra bằng cách lan trực tiếp qua sự ăn mòn thành xương của xoang, tồn tại lổ, hoăc khuyết do chấn thương cũng như thổng qua dẫn lưu xoang tĩnh mạch tủy xương ít van [10]. Sự lan rộng của nhiễm trùng qua thành sau của xoang trán có thể dẫn đến hình thành áp xe ngoài màng cứng hoặc tụ mủ dưới màng cứng.

\section{CA LÂM SÀNG:}

Trường hợp 1: bệnh nhân nữ 62 tuổi vào viện vì đau đầu dữ dội vào ngày 15 tháng 12 năm 2017.

Bênh sử: 6 tuần trước bênh nhân đau răng bên phải, được chẩn đoán viêm xoang hàm phải/ Đái thào đường type II được điều trị tại Bệnh viện địa phương 1 tuần. Các triệu chứng tắng dần, lúc này bênh nhân đau đầu dữ dội, sụp mi mắt phải và mờ mắt phải và tiếp xúc chậm. Nên bệnh nhân được chuyển đến Bệnh viện Chợ Rẫy. Sau xét nghiệm và chụp $\mathrm{CT}$ Scan, chẩn đoán xác định là: Viêm xoang hàm phải biến chứng áp xe não/ đái tháo đường type 2 . Được điều trị nội 